\title{
Modelling of fatigue damage in aluminum cylinder heads.
}

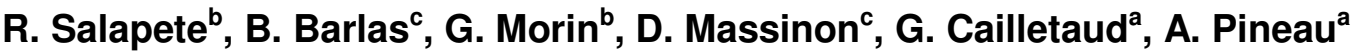 \\ ${ }^{a}$ Centre des Matériaux, Ecole Nationale Supérieure des Mines de Paris UMR CNRS 7633, BP 87, \\ 91003 Evry Cedex, France \\ b RENAULT, 67 rue des Bons Raisins, 92508 Rueil Malmaison, France \\ ${ }^{c}$ Fonderie Montupet, 67 rue J. de la Fontaine, 60181 Nogent-sur-Oise, France \\ contact author : raphael.salapete@gmail.com
}

\begin{abstract}
Car manufacturers are very much concerned with thermal fatigue damage that may cause Diesel engine to fail after a few thousand cycles on the test bench and under severe operating conditions. The alternative heating and cooling of the operative Diesel engine generates fatigue cracks, initiating from the fire deck of the cast aluminum cylinder head, which can lead ultimately to engine failure. We present here the modelling of the fatigue damage in aluminum cylinder heads : we describe the constitutive equations and the results of fatigue crack growth rate measurements. These results are used with the weight function approach to predict crack propagation lifetime of cylinder heads.
\end{abstract}

\section{INTRODUCTION}

Increase in the specific power of Diesel engines leads to severe operating conditions. The cast aluminum cylinder head of these Diesel engines is one of the most critical parts. The increase in power output results in increase of maximum temperature and build-up of high thermal gradients which may lead to crack initiation and crack propagation in the intervalve bridge region. These cracks can lead to engine failure (Fig 1a and b). It is therefore easily understood that engineers and material scientists in the automotive industry pay very much attention to this mode of failure, see eg [2-3,5,8,12].

The aluminum alloy used in the present study is a 319 ( $\mathrm{Al}-\mathrm{Si}(7 \%)-\mathrm{Cu}(3 \%)-\mathrm{Mg}(<1 \%)$, weight percent) in the T5 temper condition. In this alloy, the foundry process may produce 3D pores which can be as large as an equivalent $500 \mu \mathrm{m}$ diameter sphere [9-11]. A low cycle fatigue (LCF) specimen was specially designed to investigate the behavior of short cracks initiated from these pores. Electro-Discharge-Machining (EDM) machined artificial short cracks, with a semi-circular shape and a maximum surface length of $500 \mu \mathrm{m}$, in order to follow crack propagation from a well-known defect geometry. Conventional CT specimens were also tested at various loading ratios to determine long fatigue crack propagation rates.
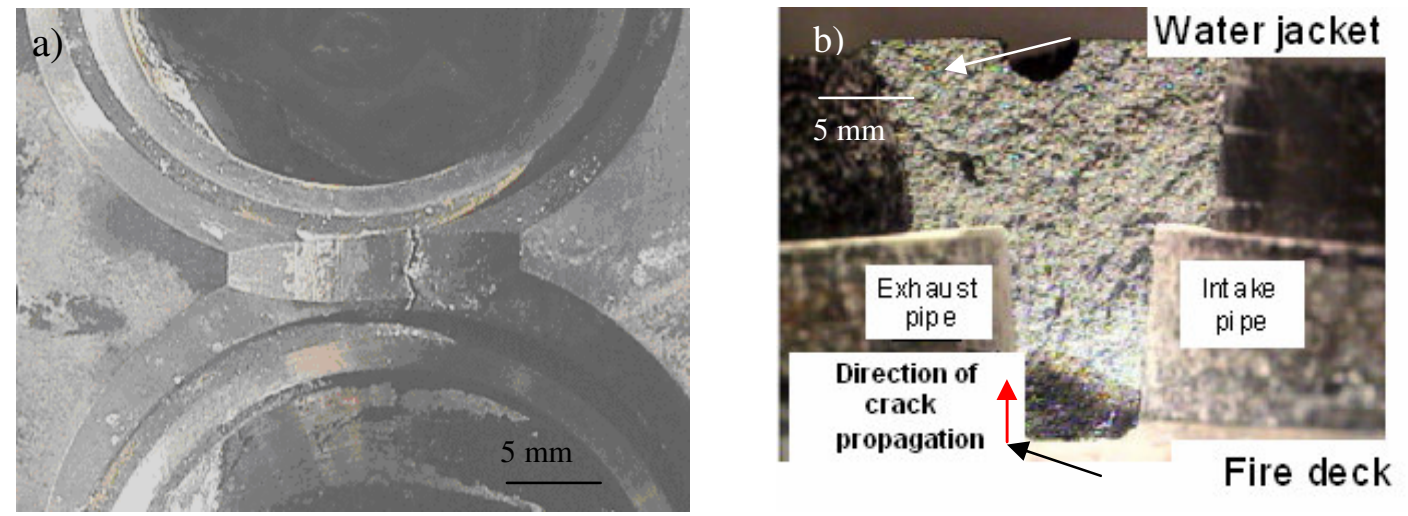

Fig. 1.a) Crack at intervalve bridge ; b) Crack propagation from the fire deck

The global methodology followed in the present study is described in [22]. The definition of the constitutive equations and a model predicting crack initiation were previously developed for this material [1,4,6-7]. They are now in use for the design of new car engines. As an example, the crack initiation at intervalve bridge can be simulated by finite element (FE) method (figure 2). A major concern of car manufacturers is now to numerically reproduce and physically control the crack 
propagation rate. The present study has been focused on crack propagation on laboratory specimens and on the comparison with real structural tests performed on cylinder heads in order to model the fatigue lifetime. This paper describes the models adopted.

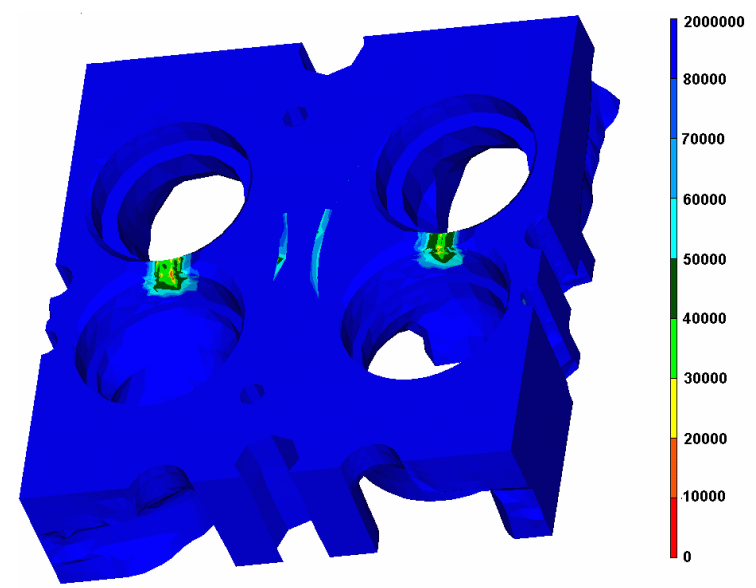

Fig. 2) Crack initiation number of cycles prediction at intervalve bridge in 3D thermomechanical calculations.

Crack propagation growth rates were studied using a special approach: the main particularity of the study is that the material has been directly extracted from Diesel cylinder heads. This has the advantage to guarantee microstructural configuration in the specimens equivalent to those in the cylinder head (Composition, porosity, secondary Dendrite arm spacing ....).

The aim of the study is to show how we can evaluate the cylinder head fatigue lifetime and how we can predict an eventual crack arrest phenomenon. Two intervalve bridge architecture were investigated in order to explain different crack growth behavior. It is shown how numerical calculations on cylinder heads and a large database for fatigue crack growth rates measurements under elastic and elastoplastic loading conditions can be used as input data for fatigue life prediction.

\section{CRACK GROWTH SIMULATION IN CYLINDER HEADS}

\section{a. The macroscopic model}

The mechanical calculation has been made in three dimensions, with ABAQUS code. The model used to calculate the strain and stresses in the structure from the knowledge of the thermal field is an extension of a classical unified elastoviscoplastic model for cyclic loadings. The constitutive equations also include ageing effects, see $[4,6-7,15]$ for further details. The kinematic variable is the tensor $\tilde{X}$, the isotropic variables are the scalar $R$ and the ageing part $R^{*}$. The yield condition is defined with a von Mises stress, as:

$$
f=J(\tilde{\sigma}-\tilde{X})-R-R^{*}
$$

with $J(\tilde{\sigma}-\tilde{X})=\sqrt{\frac{3}{2}\left(\tilde{\sigma}^{\prime}-\tilde{X}^{\prime}\right):\left(\tilde{\sigma}^{\prime}-\tilde{X}^{\prime}\right)}$ where $\tilde{\sigma}^{\prime}, \tilde{X}^{\prime}$ are the deviatoric part of $\tilde{\sigma}, \tilde{X}$. The normality rule is applied to compute viscoplastic strain rate as a power function of $f$ as:

$$
\dot{p}=\left\langle\frac{f}{K}\right\rangle^{n} \text { and } \dot{\varepsilon}_{p}=\dot{p} \frac{\partial f}{\partial \tilde{\sigma}}
$$

where $\dot{p}$ is the cumulated plastic strain rate,$\dot{\varepsilon}_{p}$ the plastic strain rate (2) and $\langle x\rangle$ the positive part of $\mathrm{x}$.

The ageing part introduces a time and temperature dependence by means of an internal variable A, starting from zero, and tending to an asymptotic value $\mathrm{A}_{\infty}$ (when the maximum ageing state is reached, $\mathrm{A}_{\infty}=1$ ). Ageing describes the 
precipitate growth (for instance, transformation from $\theta$ ' to $\theta$ precipitates ) Its evolution is exponential, with a temperature dependent time constant $\tau$ :

$$
\dot{A}=\left\langle\frac{A_{\infty}-A}{\tau}\right\rangle
$$

\section{b. Determination of the crack growth rate using a weight function approach.}

The weight function method used in the present study was derived from the work performed by Bueckner [20]. This method has been used by several authors to generalize the stress intensity factor solutions for a crack subjected to arbitrary loading $[17,21]$. For a one-dimensional variation of stresses across the potential crack plane, the basic relation between the stress intensity factor and the stress distribution is given by

$$
K_{r}=\int_{0}^{a} \sigma_{r}(x) m(x, a) d x
$$

where $\sigma(x)$ is the stress distribution and $m(x, a)$ the appropriate weight function which varies with the position coordinate $x$ and the crack length $a$. Once the weight function is known for a particular situation, the stress intensity factor can be obtained for any stress field by integration.

The interest of this method is that it allows to quickly determine the stress intensity factor for any given geometry and for any given crack length. In these calculations, realized with Zebulon FE Code [13-14], it is assumed that the crack front remains straight during propagation (see figure 3a). The weight functions for the intervalve region were determined using Buchalet and Bamford approach [21].

a)

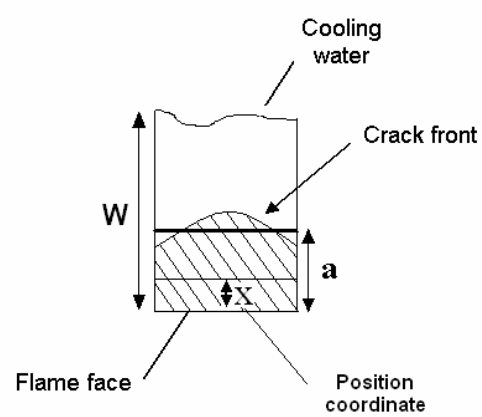

b)

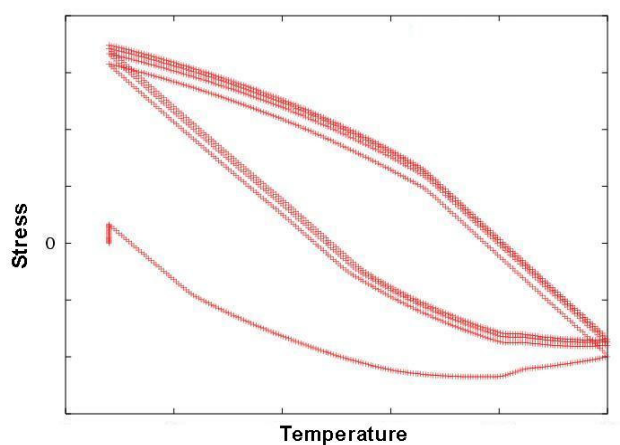

Fig. 3.a) Schematical view of crack modelisation in the intervalve bridge b) Stress-temperature curve for intervalve bridge region node.

The stress intensity factor can be calculated for any given stress distributions when these weight functions have been derived. In our case, the thermomechanical fields in the depth of the intervalve bridge are known from 3D FE calculations. Fig 3.b shows a schematic stress-temperature curve obtained at a point located near the flame face. This point is loaded in compression when the maximum temperature is reached and in tension during cooling, so that crack opening may be present at this stage.

The relation between the stress intensity factor amplitude and the crack length $\mathbf{a}$ is then given by :

$$
\Delta K_{e f f}=f\left(\frac{a}{W}\right)
$$

where $\mathrm{W}$ is the thickness between the fire deck and the water jacket, as shown in Fig.3a.

The relation between the crack growth rate and the equivalent amplitude stress intensity factor $\Delta \mathrm{K}_{\text {eff }}$ was derived from experimental data ( see section 3.c). 
Combining (4) and (5) we obtain :

$$
\frac{d a}{d N}=C \Delta K_{e f f}^{m}
$$

$$
\frac{d a}{d N}=C\left(f\left(\frac{a}{W}\right)\right)^{m} \text { and, after integration, } a=g\left(N, a_{0}\right)
$$

where $a_{0}$ is an initial crack length representative of the defects such as porosities and $N$ is the number of fatigue cycles.

\section{MATERIAL AND EXPERIMENTAL PROCEDURES}

\section{a. Material}

The material investigated is a 319 T5 alloy. The composition of this cast aluminum alloy is presented in table I. The high copper level is known to improve the high temperature behavior of this material.

\begin{tabular}{|c|c|c|c|c|c|c|c|c|c|c|}
\hline Origin & & & $\mathrm{Si}$ & $\mathrm{Cu}$ & $\mathrm{Mg}$ & $\mathrm{Fe}$ & $\mathrm{Ti}$ & $\mathrm{Zn}$ & $\mathrm{Mn}$ & $\mathrm{Ni}$ \\
\hline \multirow{2}{*}{ Cylinder head } & $\% \operatorname{mass}$ & $\max$ & 8.5 & 3.5 & 0.4 & 0.7 & 0.2 & 0.8 & 0.6 & 0.3 \\
\cline { 2 - 12 } & & $\min$ & 7 & 2.8 & 0.25 & & 0.15 & & & \\
\hline
\end{tabular}

Table I : Chemical analysis of the investigated 319 T5 aluminum alloy

This alloy presents $3 \mathrm{D}$ porosities produced by the foundry process which can be as large as an equivalent $500 \mu \mathrm{m}$ sphere. The presence of these porosities can be explained by physical and economical considerations. These pores are known to be detrimental for the fatigue lifetime of these cast alloys because they act as crack initiators. These pores have complex 3D aspect. Fig. 4 shows a section of these defects which are preferentially located in the interdendritic regions.

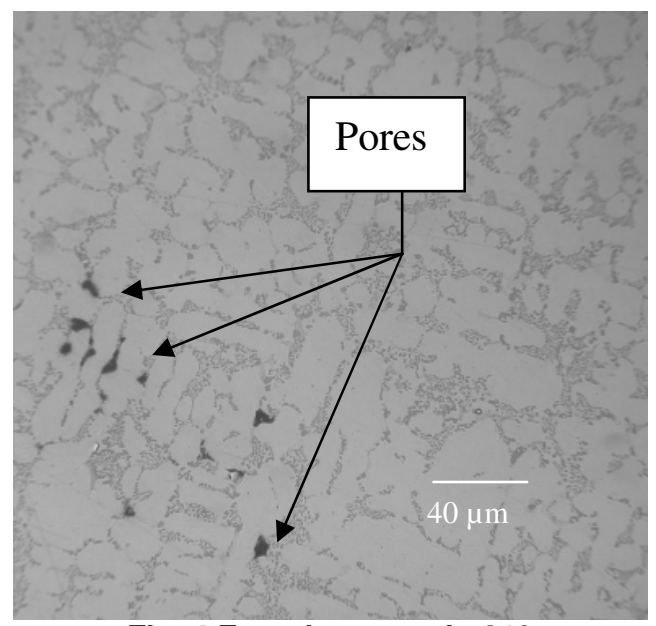

Fig. 4 Foundry pores in 319

Compact tension (CT) specimens were used to investigate long $(>1 \mathrm{~mm}$ ) fatigue crack growth rate behavior (Fig. 5a). They were directly extracted from a cylinder head. Tests were performed at 20 and $150^{\circ} \mathrm{C}$ using an electro-mechanical machine with a loading frequency of $20 \mathrm{~Hz}$. Load ratios ranging from 0.1 to 0.7 for room temperature tests and 0.1 for $150^{\circ} \mathrm{C}$ tests were applied in order to account for crack closure effect. 


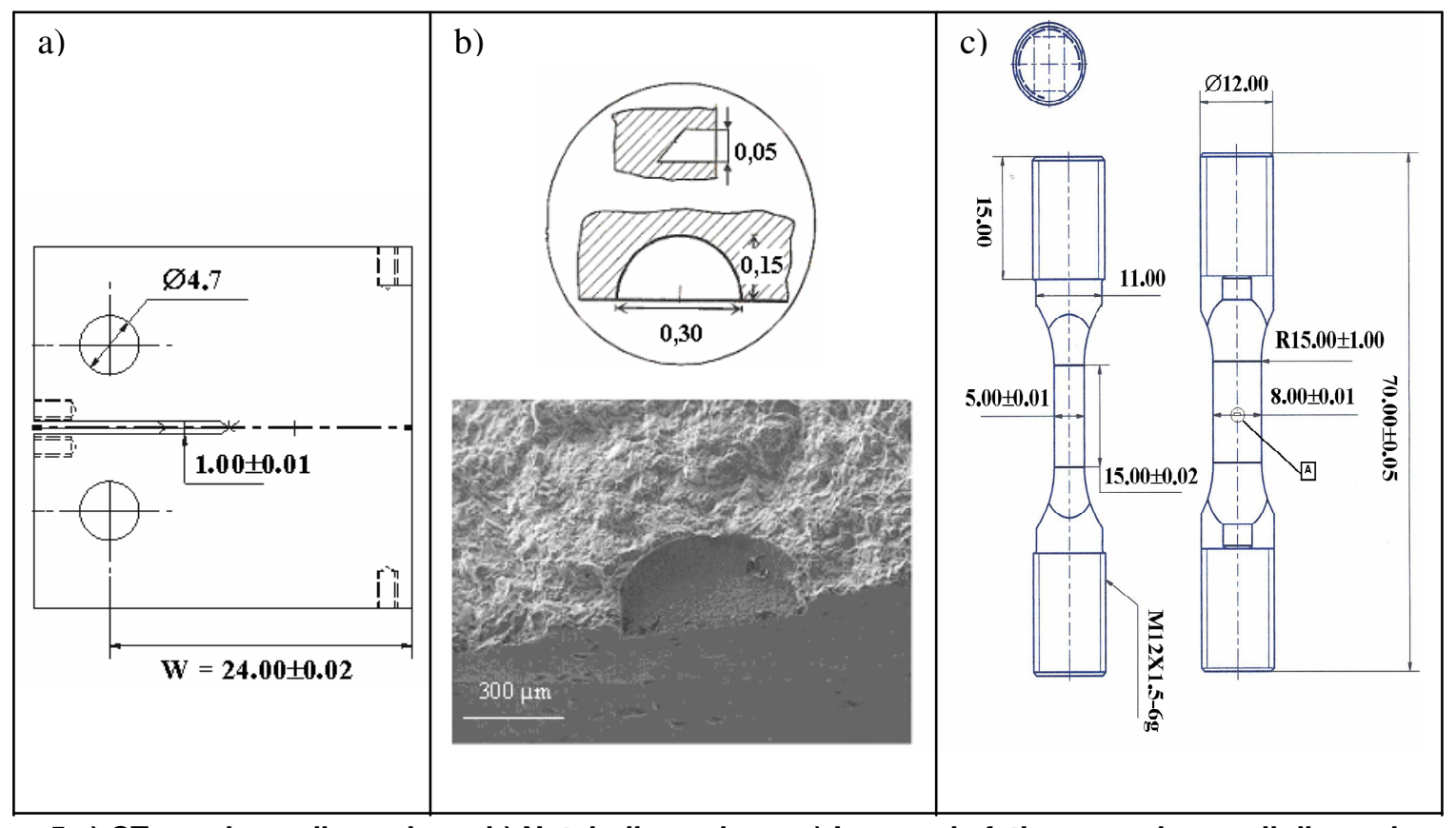

Figure 5.a) CT specimen dimensions; b) Notch dimensions; c) Low cycle fatigue specimen; all dimensions in $\mathrm{mm}$

Small fatigue crack growth tests were conducted on specimens whose dimensions are shown in figure 5.c. These specimens were tested under load and strain control conditions on an MTS servohydraulic fatigue testing system. Two test conditions were adopted: (i) tests with a load ratio of -1 with a maximum total strain ranging from 0.4 to $0.8 \%$ and (ii) tests with a load ratio of 0.1 and a maximum stress of $220 \mathrm{MPa}$. These tests were performed at 20,150 and $250^{\circ} \mathrm{C}$ with a loading frequency of $0.1 \mathrm{~Hz}$. Semi-circular notches of 150 to $250 \mu \mathrm{m}$ depths (Fig. 5.b) were machined in these LCF specimens using an electro discharge machined technique.

A QUESTAR telescope set up on the testing frame was used to observe cracks which initiate from the electromachined notch. Crack length was measured on the surface of the specimen by acquiring an image at periodic time ranging from 5 minutes to more than 3 hours for long time tests. The crack length was projected in the pure - mode I plane for analysis and the resolution of the measurement was close to a few micrometers.

\section{b. $\Delta K_{e f f}$ Calculation on low cycle fatigue specimens and on CT specimens}

The methodology used to calculate the stress intensity factor calculation corresponding to measurements realized on small crack growth tests has been presented elsewhere [19]. We recall here Haigh and Skelton's [18] expression used to define the equivalent stress amplitude

$$
\Delta \sigma_{e q}=U \Delta \sigma+E \Delta \varepsilon_{p}
$$

It corresponds to the sum of the effective stress amplitude including the closure stress $U \Delta \sigma$ and a pseudo elastic stress as the product of the Young modulus, E, and plastic deformation amplitude, $\Delta \varepsilon_{\mathrm{p}}$.

The stress intensity factor is then calculated with the expression proposed by J.C.Newman and S.R.Raju [19]. This calculation is applied to the case of a surface semi-elliptical crack under a uniform load. The stress intensity factor is calculated at the free surface point.

CT type specimens are loaded in the elastic regime. The corresponding stress intensity factor depends on crack length $\mathrm{a}$, the applied load $\mathrm{P}$ and geometrical parameters such as specimen width $\mathrm{W}$ and thickness $\mathrm{B}$.

$$
K_{C T}=\frac{P}{B \sqrt{W}} Y
$$


where $\mathrm{Y}$ is a function of $\frac{a}{W}$ ratio.

In order to take into account the crack closure effect, we have introduced a parameter q which is a function of load ratio $R$. This parameter takes into account the crack closure effect:

$$
q=\frac{\Delta K_{e f f}}{\Delta K}=f\left(R=\frac{\sigma_{\min }}{\sigma_{\max }}\right)
$$

\section{c. $d a / d N$ Calculations.}

The crack length projected in pure-mode I plane is used for the analysis. The crack growth rate is obtained from the crack length versus number of cycles curve, using a standard secant method.

One can then relate this crack propagation rate to the equivalent loading parameter using a Paris law type:

$$
\frac{d a}{d N}=C \Delta K_{e f f}^{m}
$$

\section{RESULTS AND DISCUSSION}

\section{a. Crack propagation results}

A picture of two cracks emanating from the initial defect is shown in figure 6 . The relative size of the cracks is equal on both side of the defect. The tortuous aspect of the crack path is related to the large grain size encountered in this type of cast alloy.

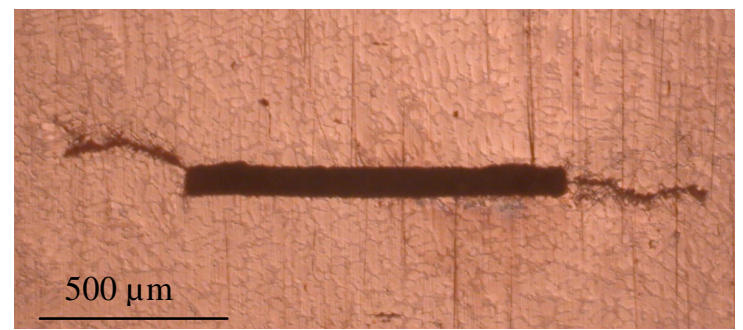

Fig. 6. Crack propagation from a known defect size

The different tests performed both on CT at 20 and $150^{\circ} \mathrm{C}$ and LCF tests at 20,150 and $250^{\circ} \mathrm{C}$ are reported in figure 7. The dependence of fatigue crack with the temperature, the plasticity level and the crack closure effect is thus shown on the graph. For long crack growth, an appropriate value of $\mathbf{q}$ is chosen. For LCF tests, the Skelton approach can be used in order to calculate an effective stress intensity factor.

Finally, the growth behavior can be described by a power-law dependence of growth rates with the calculated equivalent stress intensity factor with a slope $\mathrm{m}$ close to 4.8 .

\section{b. Crack propagation lifetime in cylinder heads}

The variation of the equivalent stress intensity factor with crack length calculated for a part-through crack in a cylinder head is shown in figure 8 . The results are reported for two structural architectures. The weight function approach presented in section 2.b is used to calculate the equivalent stress intensity factor for a part through crack present in both intervalve bridge architectures. The variation of this effective parameter with the crack length is normalized by the distance between the water jacket face and the fire deck. For the architecture 1 we can observe that the equivalent stress intensity factor is monotonically increasing with crack length. It is clear that this architecture is detrimental since it leads to a continuously increasing crack growth rate. For architecture 2, the stress intensity factor is first increasing to a maximum value and then their decreasing to reach a minimum value when the ratio of crack length over full-length reaches 0.7 . This value of the stress intensity factor is very close to the value producing crack opening. This variation is much more favorable since it suggests that crack arrest can take place at intervalves bridges. 


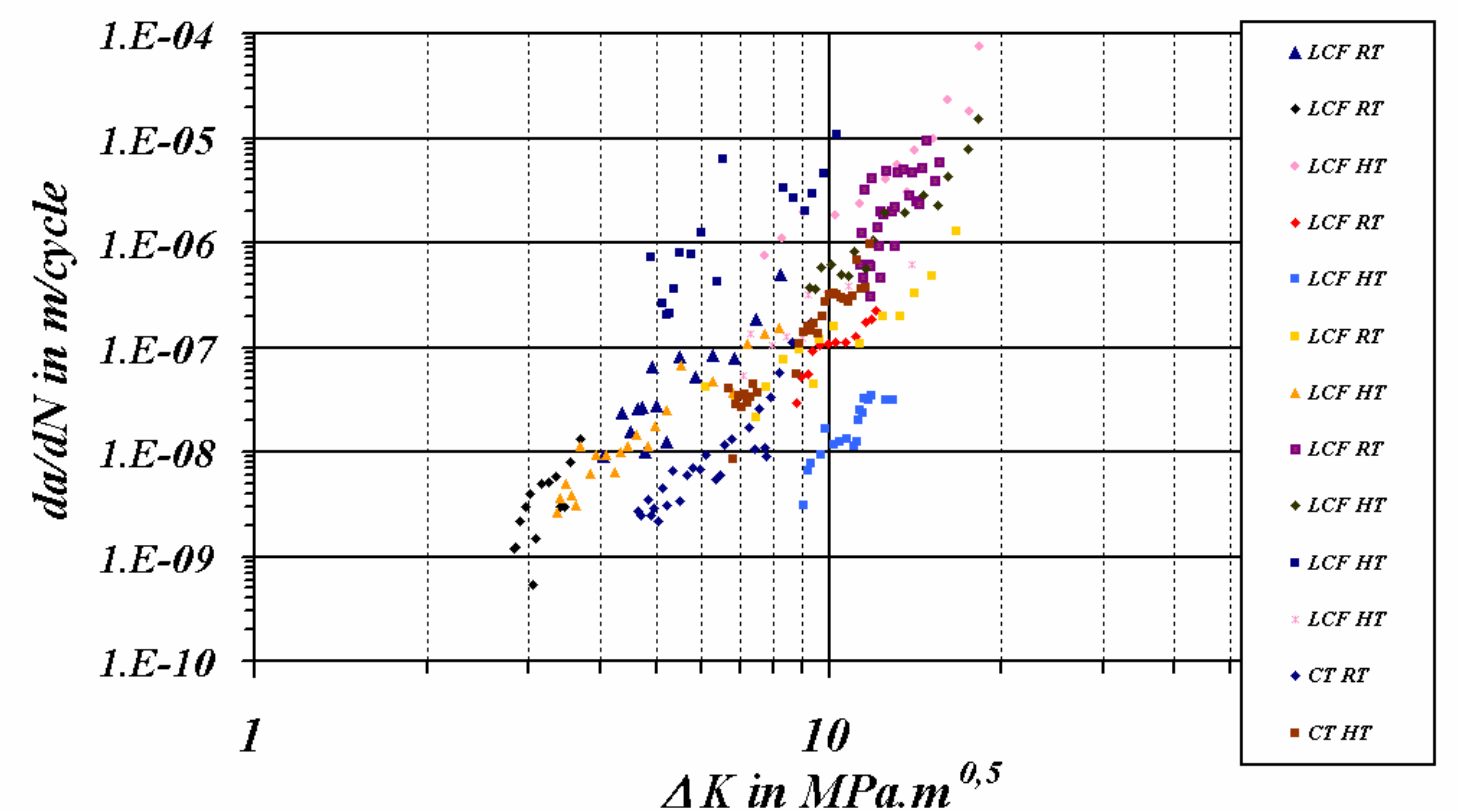

Figure 7. Crack propagation rate in 319 alloy ; RT: Room Temperature ; HT: High Temperature

Severe bench tests consisting of cycles between idle and full load and between low and high temperature were performed by Renault and Montupet to simulate damage occurring in the intervalve region during road rolling. These cycles generate high thermal gradients within the connecting area, reaching high peak temperatures for the alloy considered. One of them consists in applying thermal cycles to the cylinder heads from a minimum temperature $T_{1}$ to a maximum temperature $T_{2}$.Cracks have been observed to develop from the valves seats. This kind of tests allows to reproduce failure as a crack propagating up to the water jacket. The tests are stopped from time to time, and the corresponding crack length is measured. Curves representing crack length vs. number of cycles can then be plotted; they depend on maximum temperature, loads and on the cylinder head geometrical parameters. To evaluate the reliability of the fatigue life model, we compare the crack length vs. number of cycles for experimental and calculated results. The results for the two architectures studied are given in figure 9.

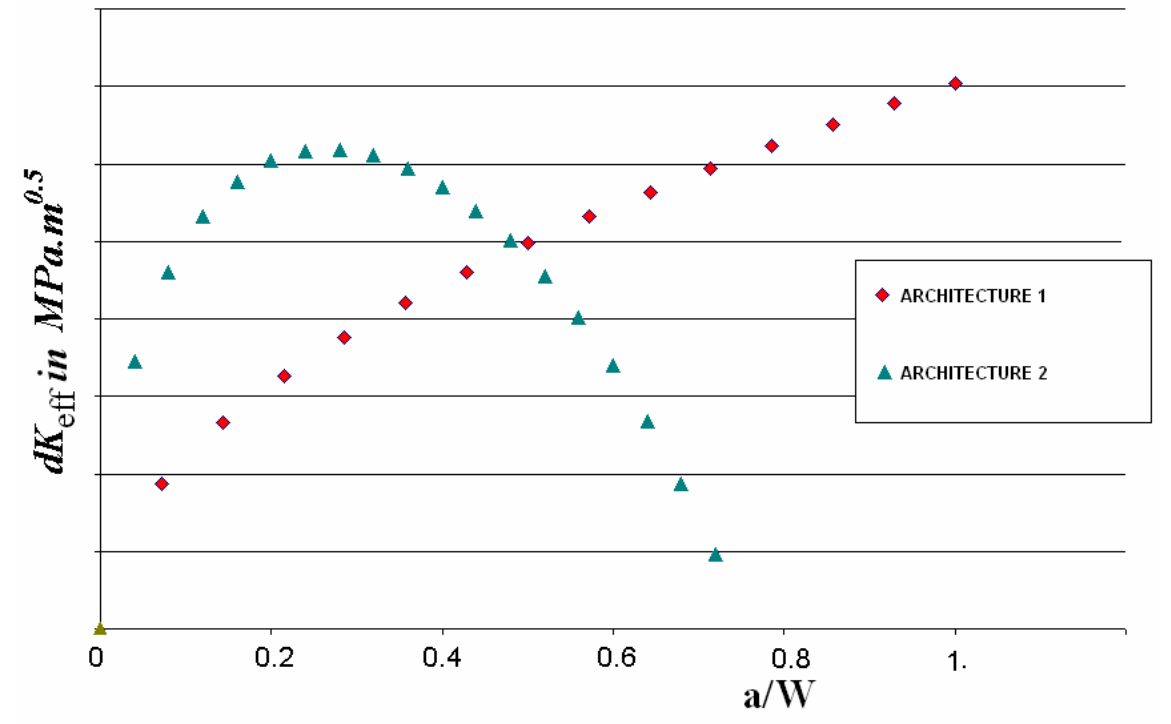

Figure 8. Equivalent stress intensity factor evaluation in two intervalve bridges depth 


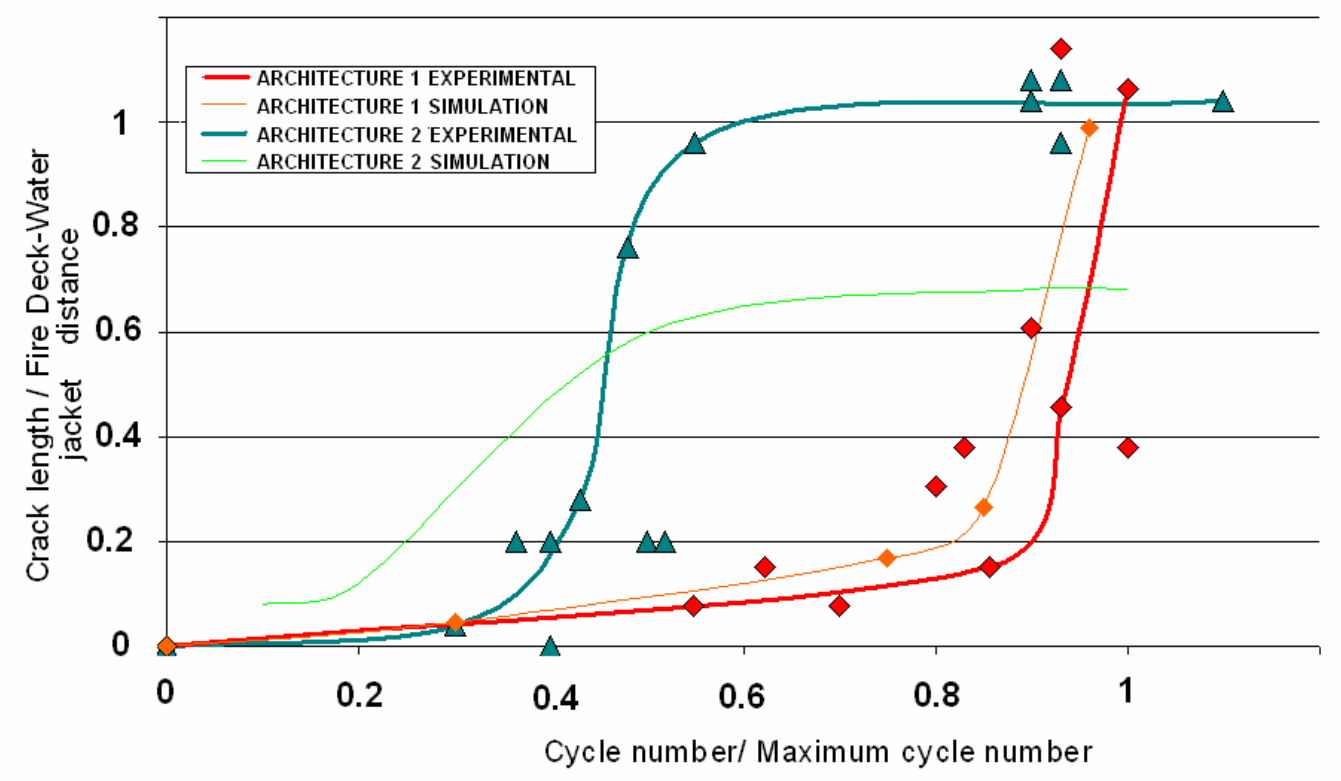

Figure 9. Comparison between experimental and numerical results from engine failure test.

\section{i. Results for architecture 1}

Two domains can be defined in the fatigue lifetime of this specific cylinder head. The first part represents fatigue crack initiation, which corresponds to a crack much smaller than the final crack length. After this relatively long initiation period, the crack is propagating very fast to reach the water jacket. Experimental and numerical results are in good agreement both qualitatively and quantitatively. In particular, the two domains observed experimentally are well reproduced by the model.

\section{ii. Results for architecture 2}

Three domains can be defined in the fatigue lifetime of this specific cylinder head. The first domain represents fatigue crack initiation, which corresponds to a crack that is smaller than 0.1 times the final crack length. The second phase corresponds to a fast propagating region where the crack is growing rapidly. The last domain represents a slow down process and a crack arrest phenomenon where the crack is no longer propagating. The comparison between experimental and numerical results clearly shows that numerical results qualitatively reproduce the observed crack arrest phenomenon and the general three domains configuration. However, the crack seems to initiate too early in the calculations and to stop at crack length smaller than the experimental one.

We are thus able to reproduce, with a relatively good approximation the crack propagation behavior for the two intervalve geometries. This method seems therefore to be a simple prediction tool for design purposes, and can be useful to develop improved design rules.

\section{CONCLUSION}

1. A method to calculate the variation of the equivalent stress intensity factor corresponding to a part-trough crack in a cylinder head and based on weight functions has been proposed.

2. A large database giving the fatigue growth rate as a function of stress intensity factor has been obtained on a 319 aluminum alloy. The influence of temperature, plasticity level and crack closure effect is taken into account by means of an equivalent stress intensity factor involving both elastic and elastic-plastic calculations.

3. Comparison between calculated and observed crack length in two tested cylinder head shows a reasonable agreement. The final behavior of the crack, corresponding to either crack arrest or failure, was numerically reproduced for these two types of geometry.

ACKNOWLEDGMENTS: Support from ANRT for one of the authors ( R.Salapete) is greatly acknowledged. 


\section{REFERENCES}

1. Aazizou, K., Calcul par éléments finis en plasticité et viscoplasticité, Phd Thesis, Ecole Nationale Supérieure des Mines de Paris, (1990).

2. Aazizou, K., Cailletaud, G., Diboine, A., Modelling of viscoplasticity and structural analysis of Diesel cylinder heads. High temperature structural Design, ESIS12, 221-242, (1992).

3. Cailletaud, G., Chaudonneret, M., De Roo, P., Plasticity and accumulation of damage in a cylinder head. Proceedings of $22^{\text {nd }}$ ISATA, Florence, (1990).

4. Nicouleau-Bourles E., Etude expérimentale et numérique du vieillissement d'un alliage d'aluminium. Application aux culasses automobiles, $\mathrm{PhD}$ thesis, Ecole Nationale Supérieure des Mines de Paris, (1999).

5. Nicouleau-Bourles, E., Morin, G., Thermomechanical fatigue of automotive engines cylinder heads, Nafems world congress 2001, The Evolution of Product Simulation, 1, 491, (2001).

6. Barlas, B., Etude du comportement et de l'endommagement en fatigue d'alliages d'aluminium de fonderie, PhD thesis, Ecole Nationale Supérieure des Mines de Paris, (2003).

7. Barlas, B., Ovono-Ovono, D., Guillot, I., Cailletaud, G., Aging and fatigue behaviour in cast aluminium alloys. Proceedings of the $8^{\text {th }}$ International Conference of Cast Aluminium Alloys, Cambridge, 13641370, (2002).

8. Thomas, J.J, Verger, L., Bignonnet, A., Charkaluk, E., Thermomechanical design in the automotive industry, Fatigue and Fracture of Engineering Materials and Structures, 27(10), 887-895, (2004).

9. Gao, Y.X , Yi, J.Z , Lee, P.D. , Lindley, T.C. , The effect of porosity on the fatigue life of cast aluminiumsilicon alloys, Fatigue and Fracture of Engineering Materials and Structures, 27(7), 559-570, (2004).

10. Lindley, T.C., Peifeng Li, Maijer, D.M., Lee, P.D., Prediction of fatigue performance in cast aluminum alloy components. Symposium on Simulation of Aluminum Shape Casting Processing, The Minerals, Metals \& Materials Society, (2006).

11. Fan, J., McDowell, D.L., Horstemeyer, M.F., Gall, K., Cyclic plasticity at pores and inclusions in cast AlSi alloys. Engineering Fracture Mechanics, 70(10), 1281-1302, (2003).

12. Shyam, A., Allison, J.E. , Jones, J.W. , A small fatigue crack growth relationship and its application to cast aluminum, Acta materialia, 53(5) , 1499-1509, (2005).

13. Besson, J., Foerch, R. , Large Scale Object-Oriented Finite Element Code design , CMAME , 142 ,165$187,(1997)$.

14. Besson, J., Le Riche, R., Foerch, R., Cailletaud, G., Object-Oriented Programming Applied to the Finite Element Method. Part II: Application to Material Behaviors, REEF, 7(5), 567-588, (1998).

15. Cailletaud, G., Depoid, C., Massinon, D., Nicouleau-Bourles, E., Elastoviscoplasticity with aging in aluminium alloys, Continuum Thermomechanics: The Art and Science of Modelling Material Behaviour (Paul Germain's Anniversary Volume), 75-86, (2000).

16. J.Lemaitre, J.L Chaboche : Mécanique des matériaux solides, Dunod, Paris, (1988).

17. Burlet, H., Vasseur, S., Besson, J., Pineau A., Crack growth behaviour in a thermal fatigue test. Experiments and calculations, Fatigue and Fracture of Engineering Materials and Structures, 12, 23133, (1989).

18. Haigh, J.R, Skelton, R.P., A strain intensity study of type 304 and 316 stainless steels. Fatigue crack growth and failure, Materials Science and Engineering, 36, 133-137, (1978).

19. Newman, J.C. , Raju, S.R. , Stress-intensity factor equations for cracks in three-dimensional finite bodies, Fracture Mechanics, 14th Symposium, 1, Theory and Analysis , 238-265, (1983).

20. Bueckner, H.F., A novel principle for the computation of stress intensity factors, Z. Agew. Math. Mech, 50, 129-146, (1970).

21. Buchalet C.B., Bamford W.H., Stress intensity factor solutions for continuous surface flaws in reactor pressure vessels , Mechanics of Crack Growth, ASTM STP 590, pp 385-402, (1976)

22. Salapete, R. , Barlas, B. , Nicouleau, E., Massinon, D. , Cailletaud, G. , Pineau, A. , Fatigue life predictions of aluminium cylinder heads, Fatigue Design 2005, 2 , 57 , (2005). 